\section{Prescient words on comets and life}

The landing of the Philae probe on comet 67P/ChuryumovGerasimenko last month has led to speculation that comets might have delivered the building-block elements of life to Earth - an idea anticipated by the French astronomer Camille Flammarion more than a century ago in his 1880 book Astronomie populaire.

Flammarion wrote of comets: "Their importance would be much greater still if they should be found to carry in them the first combinations of carbon, for it is probable that it was by these combinations that vegetable and animal life commenced on the earth and the other planets and thus these vagrant bodies might be the sowers of life on all the worlds!"

Milton Wainwright University of Sheffield, UK.

m.wainwright@sheffield.ac.uk

\section{Pool resources for protected areas}

Protected conservation areas face huge challenges globally (see J. E. M. Watson et al. Nature 515, 67-73; 2014). But examples that are effectively funded and managed can be found in Namibia and in the Brazilian Amazon. In our view, these models are so successful that they could be adapted and replicated around the world.

In Namibia, the Ministry of Environment and Tourism awards exclusive tourism concessions to communities that are next to protected areas and have formed conservancies. This attracts millions of dollars in infrastructure investment, empowering communities with economic activity and employment opportunities and creating strong incentives to live with and protect wildlife.

The Amazon Region Protected Areas programme safeguards a staggering $15 \%$ of the Brazilian

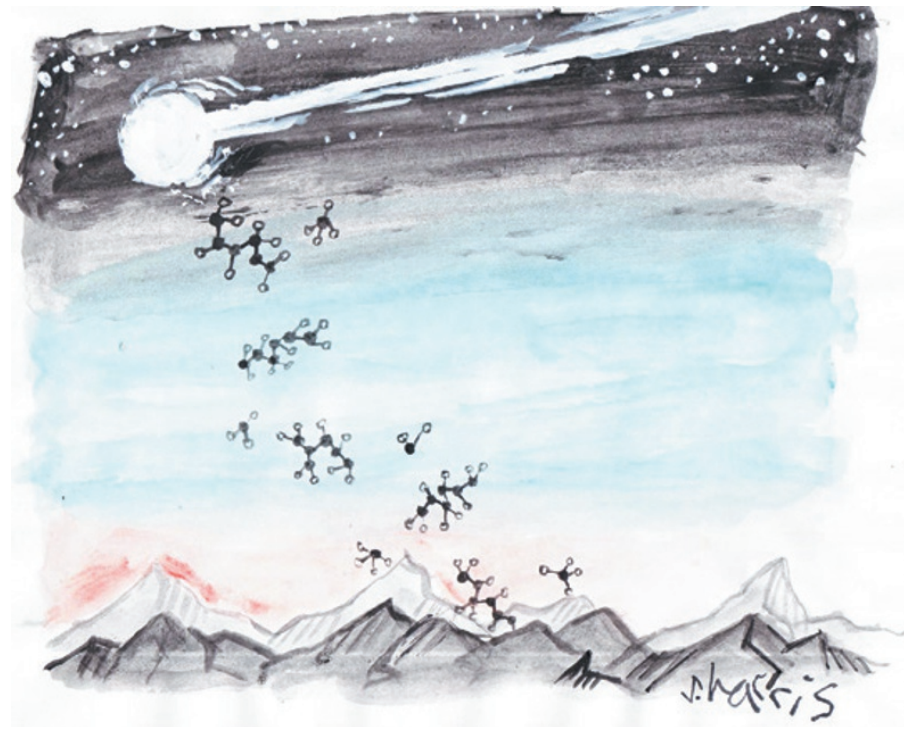

Amazon. Funded through an innovative partnership of public and private donors, it has secured US $\$ 215$ million to cover costs over the next 25 years. Brazil is gradually stepping up its own contributions to ensure full and permanent funding. Jon Hoekstra, Meg Symington World Wildlife Fund, Washington DC, USA.

Chris Weaver WWF-Namibia, Windhoek, Namibia. jon.hoekstra@wwfus.org

\section{Research agency will lose autonomy}

On 1 January 2015, a large new government office will take over Hungary's research-grant agency for basic science, OTKA. This will assume all budget management for research, development and innovation - destroying what the European Science Foundation has described as the agency's "high degree of political autonomy".

A report by the foundation in November hailed OTKA as "the crown jewel of Hungary's $\mathrm{R} \& \mathrm{D}$ system; it is a professionally managed research council, whose procedures conform to the highest international standards. For several years, it has been in a constant process of improving its approaches and instruments, and it is obvious that OTKA will continue to do so". This view accords with that of most Hungarian scientists.

You note that "in Hungary, where the pluralism is under threat, the writing is on the wall" (see Nature 515, 7-8; 2014). No scientist in Hungary expected that this prophecy would come true so soon.

András Váradi Institute of Enzymology, RCNS, Hungarian Academy of Sciences, Hungary.

János Kertész Central European University, Hungary. varadi.andras@ttk.mta.hu

\section{Flood resilience a must for delta cities}

Conventional methods of flood protection such as levees are no longer adequate against the increased risk of flooding in Asian delta cities. We call for a multipronged approach that focuses on long-term, sustainable solutions to increase these cities' resilience to flooding (see also L. Giosan et al. Nature 516, 31-33; 2014).

In October, Ho Chi Minh City in Vietnam experienced recordbreaking flood levels in the Saigon River for the fifth consecutive year and for the eighth time in the past decade. Among the contributing factors are massive urban development, reduced river-storage capacity, land subsidence from unregulated groundwater extraction, extreme storm events and rising sea levels. Similar disruptions in Beijing, Jakarta and Manila have also led to catastrophic floods.

Several strategies exist to increase resilience against flooding. These include developing urban infrastructure to decrease the effects of extreme rainfall (for example, by incorporating sustainable living green roofs and making pavements permeable); building in harmony with natural-systems dynamics, as in the Room for the River (go.nature.com/hqjld5) and Sand Motor (go.nature. com/e24ecq) projects in the Netherlands; and incorporating flood-risk forecasts for downstream urban areas into reservoir management. Ruben Dahm* Deltares, Delft, the Netherlands.

ruben.dahm@deltares.nl ${ }^{*}$ On behalf of 4 correspondents (see go.nature.com/qmy9vg for full list)

\section{What football can teach science}

One solution to the challenges posed by voluntary peer review (M. Arns Nature 515, 467 (2014) and see Nature 515, 480-482; 2014) might be to create a professional, independent body of reviewers that could be for hire by journals - rather like the professional referees used in football.

These reviewers could be funded by contributions from research councils, charities and end-users - namely, scientific journals and funding bodies.

Such a system could put an end to rigging scandals and to poorquality, unprofessional or biased peer review, as well as improving the speed and consistency of the refereeing process. It could even offer stable employment for thousands of PhD graduates. Arturo Sala Brunel University London, Uxbridge, UK. arturo.sala@brunel.ac.uk 